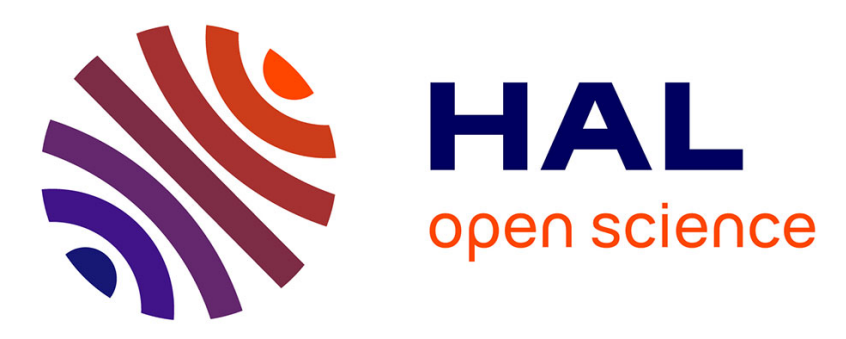

\title{
Review Article: The Bergen Electronic Edition of Wittgenstein's Nachlass: Wittgenstein's Nachlass
}

David Stern

\section{To cite this version:}

David Stern. Review Article: The Bergen Electronic Edition of Wittgenstein's Nachlass: Wittgenstein's Nachlass. European Journal of Philosophy, 2010, 18 (3), pp.455-467. 10.1111/j.14680378.2010.00425.x . hal-01625868

\section{HAL Id: hal-01625868 \\ https://hal.science/hal-01625868}

Submitted on 29 Oct 2017

HAL is a multi-disciplinary open access archive for the deposit and dissemination of scientific research documents, whether they are published or not. The documents may come from teaching and research institutions in France or abroad, or from public or private research centers.
L'archive ouverte pluridisciplinaire $\mathbf{H A L}$, est destinée au dépôt et à la diffusion de documents scientifiques de niveau recherche, publiés ou non, émanant des établissements d'enseignement et de recherche français ou étrangers, des laboratoires publics ou privés. 


\begin{tabular}{|c|c|c|c|c|c|c|}
\hline \multirow{2}{*}{ a } & E J O P & 425 & \multirow{2}{*}{$B$} & Dispatch: 29.7 .10 & Journal: EJOP & CE: Ashwini \\
\hline & Journal Name & Manuscript No. & & Author Received: & No. of pages: 13 & PE: Nasreen/Mini \\
\hline
\end{tabular}

DOI: $10.1111 /$ j.1468-0378.2010.00425.x

\title{
Review Article
}

\section{The Bergen Electronic Edition of Wittgenstein's Nachlass}

\author{
David Stern
}

\author{
Ludwig Wittgenstein, Wittgenstein's Nachlass: Text and Facsimile Version. The Bergen \\ Electronic Edition. Oxford: Oxford University Press, 2000. \\ Windows Individual User Version. Text and Facsimiles, £1100.00+VAT; Text Only, \\ $£ 700.00+$ VAT. Network Version, Text and Facsimiles, £2500.00+VAT; Text Only, \\ $£ 1750.00+$ VAT
}

\section{Introduction}

Wittgenstein's Nachlass consists of over 20,000 pages of manuscripts and typescripts. Because Wittgenstein published barely 25,000 words of philosophical writing during his lifetime-the Tractatus Logico-Philosophicus (1922) and a very short conference paper-the papers that he left unpublished have played an unusually large role in the reception of his work. The posthumous publications, almost all of them based on materials in his Nachlass, contain well over a million words. As the Nachlass as a whole contains approximately three million words, one might estimate that roughly a third of Wittgenstein's writing is in print. However, as much of the material that was not edited for publication consists of early versions, rearrangements, and other source material for the previously published material, one could argue that considerably more than a third of his Nachlass has already seen the light of day in one form or another. On the other hand, because Wittgenstein never copyedited any of these papers for publication, each of the posthumous books and papers called for substantial editorial decisions about the content, and how to present it. Consequently, almost all of the twentieth-century publications from the Nachlass were extensively edited, often with little or no indication of the relationship between the source texts and the published material, and so one could argue that very little of the Nachlass has been available in print. ${ }^{1}$ A number of more recent publications, such as the criticalgenetical German language edition of the Philosophical Investigations (Wittgenstein 2001) and the German-English scholars' edition of the Big Typescript (Wittgenstein 2005) are sophisticated critical editions. They make use of the information provided in the Bergen edition to present not only the final state of the text, but also such matters as undecided variant wording, marginal marks, and the different stages of revision, by means of footnotes and the use of an elaborate apparatus. The 'Vienna edition' of the manuscripts and typescripts from the 1929 to 1932 period (Wittgenstein 1993a, 1994-) however, is the product of a separate editing project.

The Bergen electronic edition, freed from the constraints of print publication, provides much more detailed information about each page of the manuscripts and typescripts that make up the Wittgenstein papers. The organizing principle is Georg Henrik von Wright's

European Journal of Philosophy m:u ISSN 0966-8373 pp. 1-13 (C) 2010 Blackwell Publishing Ltd., 9600 Garsington Road, Oxford OX4 2DQ, UK and 350 Main Street, Malden, MA 02148, USA. 
catalogue of the papers, which lists 83 manuscripts (101-183), 46 typescripts, (201-246), and 11 dictations (301-11). There are approximately 5000 pages of typescripts, a few manuscripts on loose sheets, with the remainder written in bound volumes and notebooks. All references to a specific place in the Nachlass are provided in terms of a manuscript number and page number, and search results are always displayed in that order. ${ }^{2}$

In the early 1990s, the first director of the Bergen Wittgenstein Archive, Claus Huitfeldt, a Norwegian philosopher and computer specialist, led the development of the multielement coding system (MECS) used to produce the digital transcriptions of the source texts. This 'machine-readable version', a set of marked-up and encoded transcriptions that aims to record as much of the relevant information about the text as the editors consider appropriate, is the basis of the Bergen electronic edition, but is substantially different from it. $^{3}$ The machine-readable version can be thought of as a database that systematically encodes the results of the transcribers' work; the Bergen electronic edition was generated from that database. Transcription, coding, and editing these materials took over ten years, forty man-years of work, and a budget of 14 million Norwegian kroner, or approximately $£ 1,000,000$ at the 2001 rate of exchange. ${ }^{4}$ The Bergen Edition comprises over 21,000 colour facsimiles of almost every page of Wittgenstein's papers, two different editions of the 3 million or so words on those pages, and a custom-built search engine.

The distinction between the database containing the machine-readable transcriptions, the edited versions of that material presented by the Bergen Electronic Edition, and other realizations of that database may seem to be an arcane point of electronic editorial philology to scholars who simply want to read the Nachlass. However, those machine-level transcriptions have already served as the basis for other presentations of those texts, both in the server-based Intelex edition of the Bergen Electronic Edition and the open-access webbased Discovery project currently under development. Furthermore, that distinction between the transcription, usually recorded in computer code, and the resultant editions, prepared for the ordinary reader, is essential for an appreciation of two crucial differences between digital and print publishing. Digital publishing not only opens up the possibility of new ways of working with texts, but the software that provides access to a digital text can also prevent one from doing things that we take for granted with books, such as making copies. ${ }^{5}$ At first sight, it may look as if a scholarly digital edition of an author's writing is no more than an up-to-date repackaging of familiar components, each of which can be found in the world of scholarly print publishing, such as facsimiles, the concordance, and the critical edition. However, a published book is a physical object, a bound codex, a text that has taken on a definite form. A digital edition is a virtual object, presented in a software package, in which a text can take on multiple forms. Printing a scholarly edition of an author's writing requires that the editor settle on a specific way of presenting the text. A digital edition, on the other hand, permits multiple ways of presenting and manipulating the transcription of the text. While both print and digital editing involve transcription, digital editing requires additional decision-making:

When one is transcribing for a traditional edition, the choices are bounded by the characters available in the printer's fount; furthermore, the end of the transcription is its printing, and not its distribution in electronic form. But one can expect a computer-readable transcription to be searched, analyzed, and edited in ways not possible with a printed transcription.(Robinson 1997: 150)

It is also important to distinguish between limitations due to choices made in producing the encoding protocols, limitations that could only be overcome by first altering those

(C) 2010 Blackwell Publishing Ltd. 
protocols and then revising the transcriptions, and those due to Folio Views, the software package used in the Bergen Electronic Edition. The version of Folio Views in the Bergen Electronic Edition was developed in the early 1990s, when Windows 3.1 was the standard operating system and only computer experts knew how to use a web browser. Because Folio Views is employed in the Past Masters series of electronic editions of the works of many of the most important figures in the history of philosophy, it is a familiar environment for many philosophers. Because the customer base is so small, it is sold at a price that only well-endowed institutions can afford. As of spring 2007, approximately 150 copies of the complete edition (text and facsimiles), 40 copies of the text-only version, plus an additional 70 copies of the first volume (text and facsimiles) had been sold. In other words, the market for such technology has, so far, guaranteed it a 'niche' role where it is only accessible to relatively few researchers. However, as the results of the work of the first generation of users of this software reaches a broader audience, and as the transcription work of the WAB is more widely disseminated via initiatives such as the Discovery project, which will make some 5000 pages of the Nachlass freely available on the Web, we can expect that the digital turn in Wittgenstein studies, like the web browser, will eventually reach a wider audience. In order for the Bergen transcription of the Wittgenstein Nachlass to be made available in this way, the original MECS code must be translated into XML, the emerging standard for web-based encoding. While the editor's work is done when a traditional scholarly text is published, an electronic text, like any other software, must constantly keep up with emerging standards or rapidly become obsolete. Alois Pichler, who took over the leadership of the Bergen Wittgenstein Archive just as the Bergen Electronic Edition was published, has done precisely what was needed to ensure that the work of the Archive remains not only relevant but also innovative. ${ }^{6}$ Another promising development is the publication of the Innsbruck electronic edition of Wittgenstein's correspondence (Wittgenstein 2004), which includes hyperlinks to a substantial and informative commentary, biographical information about people, places and literature mentioned in the letters, and a timeline of Wittgenstein's activities.

\section{Using the Bergen Electronic Edition}

On starting up the software, the reader arrives at a Contents page containing links to six options. Three of them are comparable to the 'front matter' of a printed book: an introduction to the Nachlass and the editorial decisions, a user guide explaining how to use Folio Views, and the usual 'Read Me' file about installation. ${ }^{7}$ The other three provide three different ways of looking at the papers: colour photographs of each page of the source text, a detailed 'diplomatic' edition of that text that shows as much information as possible, and a 'normalized' edition that leaves out such matters as variant wording and information about deleted text. ${ }^{8}$ Roughly speaking, the 'diplomatic' edition shows a letter-by-letter representation of every semantically significant mark on the page, while the 'normalized' edition shows each word at the end of the writing process. The diplomatic edition is a detailed representation of the state of the original manuscript; the normalized edition is an edited text that can be read more smoothly. Thus, the diplomatic edition shows misspelled words, and words written in Wittgenstein's letter-replacement code as they stand on the page; it includes words that are crossed out, deleted, inserted or subsequently revised. The normalized edition corrects spelling, shows words written in code in their decoded form, and includes only the last version of wording that has been revised. Links between each page of the normalized and diplomatic editions, and the facsimiles, make it

(C) 2010 Blackwell Publishing Ltd. 
easy to move between the different representations of the text, and to check on the editorial work. Close readers interested in rejected alternatives, marginalia, and the intricacies of Wittgenstein's rewriting process will ordinarily turn to the diplomatic edition; readers who prefer a clean final text will usually prefer the normalized edition. In some cases, such as an unedited typescript, the differences between the three are negligible, and it is often easiest to bring up the facsimile of the typescript. In others, where the text has been repeatedly revised, a careful reader will need to move between all three representations.

The transcriptions include an elaborate system of 'tags' that track many semantically significant features. One can limit a search to a specified period, volume or group of volumes, to words written in German, in Wittgenstein's letter replacement code, English, French, or Latin; to symbols in logical, mathematical, set-theoretical notation, musical, or miscellaneous notations; to people, a category that covers not only historical figures, famous people, family and friends, but also fictional characters; or for one of the many diagrams and drawings. In each case, clicking on that search option opens a drop-down list of relevant choices; clicking on any of those choices lets one know how many hits there are for that search term. Results can be displayed in a variety of customized formats. It is easy to combine a number of different terms, for instance to collect results for a family of words. Because one searches a previously generated database, results are displayed immediately, even for complex searches with hundreds of hits. Both editions also include 2,500 images of Wittgenstein's drawings, diagrams, musical scores, and similar material that cannot be encoded using the specialized mark-up language. The careful handling of the extensive range of graphical symbols, which are often essential to the accompanying discussion, is particularly impressive. ${ }^{9}$

When the Bergen Electronic Edition was produced, it was expected that users would insert one of five data CDs as needed in order to view the facsimiles. Fortunately, there is plenty of room on today's hard drive for 4GB of images, and it is relatively simple to redirect the software to the new location. Similarly, while the image display program provided is incompatible with Windows XP, one can easily replace it with the viewer of one's choice.

The version of the online (server based) edition available at the time of writing did not include any images at all, though there were plans to do so eventually. An even bigger limitation is that it only displays one very short passage at once. In the Windows package, the diplomatic or normalized edition provides a window that can show the complete set of texts, from the beginning of MS 101 to the end of TS 310. It is easy to customize the display to show selected texts, or to flip to a 'contents' display in order to find a given page more easily, but it is crucial that one can move to any part of the text without any delay. At first, it can seem overwhelming, but it is enormously helpful to be able to have as many windows open as one needs, each showing the relevant passages in full. With the online edition, one can only view a few paragraphs at once, even the simplest searches take a long time if one is accessing the server via a remote connection, and the ability to 'cut and paste' is disabled. In the Windows version of the Bergen Electronic Edition, with a little training in the appropriate techniques, one can cut whatever parts one needs to examine further and paste them into a word processing document. The cut and paste option is admittedly fairly crude, as there is no control over the format of the output, which shows only part of the detailed onscreen display, yet still leaves a host of data and formatting that one needs to remove manually before one has a clean text to work with. 'Export to MS Word' or 'ASCII text only' options would have been welcome.

Before the publication of the Bergen edition, the only public access to the Nachlass was by means of microfilm, or transcripts of unpublished sources of the Philosophical 
Investigations produced and circulated by G. H. von Wright, assisted by Heikki Nyman and André Maury. Indeed, it was not until the end of the 1960s, with the production of the 'Cornell' microfilm of the Nachlass, and the publication of von Wright's catalogue and guide to 'The Wittgenstein Papers' (1969), that research on the Wittgenstein papers became possible. Anyone interested in working on the Nachlass should start by reading the most recent version of von Wright's catalogue, and his pioneering studies of the composition of the Tractatus and Philosophical Investigations (von Wright 1982; see also Stern 1996a, 1996b). Despite the difficulties involved in working with this material, the promise it held for a deeper understanding of Wittgenstein's work meant that a remarkably large number of books were written during the 1980 and 1990s that made extensive use of it.

Garth Hallett's Companion to Wittgenstein's 'Philosophical Investigations' (1977) was the first book to give multiple references to the sources of each remark in the Philosophical Investigations and to include frequent quotations from the Nachlass. Hallett also provided a reading of the text that turned on an account of the development of Wittgenstein's thought between the Tractatus and the Philosophical Investigations. Peter Hacker and Gordon Baker's multi-volume commentary (Baker and Hacker 1980, 1984; Hacker 1990, 1996) provided a great deal of information about the multiple manuscript and typescript sources of remarks in the Philosophical Investigations. Much of this information was based on the painstaking and detailed research by von Wright and Maury on the manuscript and typescript sources of each remark in Part I of that book, now also available in Maury's list of the 'Sources of the Remarks in Wittgenstein's Philosophical Investigations' (1994) and appendixes to the critical-genetical edition of the Philosophical Investigations (Wittgenstein 2001). The Bergen Electronic Edition does facilitate the exploration of these-and other-processes of rewriting connecting the various stages of revision, compilation, reorganization, selection, and rearrangement that are characteristic of his writing. However, there are no hyperlinks connecting earlier and later drafts, and there are no tags marking these connections that would enable one to search for them systematically. In practice, it is rarely difficult to find earlier or later drafts of a given passage, as one just has to use the main search window to look for a few of the less common phrases in the remark in question. Readers wishing to explore the systematic links between the Philosophical Investigations and its sources, or the complex process of revision that leads from the manuscript notebooks from 1929-1932 to the various typescripts based on them, will find a great deal of invaluable guidance in the previous literature on the topic. ${ }^{10}$ However, it is unfortunate that none of this information was built into the Bergen Electronic Edition, and given the proprietary nature of the software, there is no facility for an individual researcher to add it in.

The basic unit in Wittgenstein's process of revision is the remark, a passage that may be as short as a single sentence, or as long as a sequence of paragraphs stretching over several pages. Typically, remarks are separate from one another by a blank line, and are usually numbered sequentially in the more polished typescripts-each numbered section in Part I of the Philosophical Investigations is a remark. Unfortunately, there is no systematic way of tracking or searching for remarks in the Bergen Electronic Edition, and line breaks are not shown in either of the editions. When I discussed the prospect of an electronic edition in 1996, I certainly imagined that it would be as easy to trace Wittgenstein's process of revision as his use of key terms, and it is disappointing that the Bergen Electronic Edition does not support searches for remarks or blank lines between paragraphs. Coding for blank lines was included in MECS, the Bergen transcription protocol, but due to problems with the automated conversion process used to move the MECS data into the Folio Views format, that information was not included. Line breaks and the beginning of remarks will be shown in the improved diplomatic and normalized editions of the Wittgenstein

(C) 2010 Blackwell Publishing Ltd. 
Nachlass in the next-generation Discovery website. ${ }^{11}$ The display has also been made more intuitive; for instance, insertions above or below a line show up as superscripts or subscripts.

Wittgenstein often put marginal marks, or sigla, in the margin at the beginning of a remark to indicate plans for revision or reorganization, but never provided a key. There is some consensus about the overall interpretation of a few of the most common signs. Examples include ' $S$ ' for 'Schlecht', (bad) a ' $/$ ' for manuscript remarks to be transcribed in a typescript of selections from that manuscript, and wavy lines in the margin as a way of indicating his dissatisfaction with the wording (the latter is also used under particular words for the same reason). However, such construals are at best reasonably well established hypotheses. While the sigla are included in the diplomatic transcription (but not the normalized one), they do not show up in a search, and the transcription can be inconsistent. Tuomas Manninen pointed out that two capital 'L's, sometimes written somewhat sloppily, are used frequently in MS 137, but are transcribed as '1.h.' on pages 86a-b, 'h.l.' on pages $88 \mathrm{a}-\mathrm{b}$, and 'l.l.' on page $91 \mathrm{~b}$, even though there is very little variation in the way they are written on those pages. According to Schulte $(1993,6)$ 'L.L.' indicated that the relevant remark was 'to be included in MS 144, a loose-leaf (= L.L.) folder on whose contents Part II of the Philosophical Investigations is based'.

There has been very little explicit discussion of Wittgenstein's use of sigla and other related editorial techniques in his manuscripts. ${ }^{12}$ The only extended discussion of this issue in print is by Josef Rothhaupt (1996: 327-39; 2008.) Indeed, Rothhaupt observes that even in the cases that seem most straightforward, the evidence for the usual reading is not unequivocal. For instance, there is an ' $S$ ' in front of the first manuscript record of the Nestroy passage that became the motto to the Philosophical Investigations. Clearly, this shows that we cannot take an ' $\mathrm{S}$ ' as a sign that Wittgenstein had given up on using a remark, or had decided that it was plain 'bad'. Perhaps it meant only that he wasn't entirely happy with it, or that he was planning to have some of the remarks typed up and didn't want to include the remarks marked ' $S$ '. We cannot rule out the possibility that Wittgenstein used the same marks for different purposes in different manuscripts, or at different stages of revision. Indeed, in the case of some of the more elaborate sigla, it is far from clear whether the differences between certain inscriptions are merely orthographic, or should be taken as distinguishing different sigla, let alone how the various sigla interact when several are written on top of one another. Given that we lack a good grasp of the semantics of Wittgenstein's sigla, the question of how to reidentify a siglum-which marks count as the same siglum - becomes pressing. Recently, Rothhaupt (2008) has proposed that a 'Kringel' - a circular siglum, or round squiggle-indicates Wittgenstein's selection of remarks for a book, complete with motto and preface, drawing from manuscripts written between October 1929 and September 1931. Rothhaupt calls this the 'Kringel Buch' text corpus. This is an intriguing and extremely promising proposal that brings together many of Wittgenstein's most interesting writings from this period in an unexpected way, and I regret that space limitations prevent me from discussing it further here.

\section{Results of a Close Study of the Transcription}

Working with Tuomas Manninen, my graduate student research assistant at the time, we compared passages from the diplomatic edition of four manuscripts $(105,114,142$, and $183)$ and four typescripts $(226,227 \mathrm{a}, 233 \mathrm{~b}, 235)$ against the facsimiles, and a published version, in those cases where one was available. ${ }^{13}$ I chose a variety of different materials

\footnotetext{
(C) 2010 Blackwell Publishing Ltd.
} 
for review, from different periods of Wittgenstein's career, and of different levels of editorial complexity. We looked not only for errors in transcription, but also for places where the transcription methods were insufficient to capture details in the source text.

Like Joachim Schulte, the only other reviewer who has reported on extensive checking of the quality of the editing, we found that the quality of the transcribers' work varied: 'mostly it was good, sometimes it was excellent, and occasionally it was disappointing'. ${ }^{14}$ In the best cases, we found a mistake every few pages; at worst, an average of several mistakes per page. The vast majority were minor errors of transcription, punctuation, or spelling, and some were certainly debatable; the most serious involved the complete omission of phrases or sentences. Looking at a variety of materials not only allowed us to look at the work of different transcribers, but also to consider some of the strengths and weaknesses of the transcription system itself.

TS 226 is an unpublished translation into English, by Rush Rhees, of the beginning of the prewar version of the Philosophical Investigations. ${ }^{15}$ We were impressed that there were only a few small mistakes in the 12 pages of the diplomatic edition of TS 226 that we reviewed, a typescript with dozens of handwritten changes on most pages, often on every single line. However, we found the handling of typewritten phrases that had been marked for relocation, using square brackets to show the whole passage affected, less than perspicuous. There is a striking example in Wittgenstein's discussion of the difficulty of conceiving of a game as always bounded by rules. In the sentence beginning 'I can well imagine that someone is always in doubt before he opens the door of his house whether a chasm may not have opened on the other side of it ...' (TS 226, 59; cf. Philosophical Investigations \$84), Wittgenstein had circled 'is always in doubt' and drawn an arrow showing that it should go after 'house,' with the words 'as to' immediately afterward. This is shown in the diplomatic edition with square brackets around the whole passage affected, rather than the words that are relocated, as follows:

I can well imagine that someone [is always in doubt before he opens the door of his house $\ll \downarrow$ as to $\gg$ whether a chasm may not have opened on the other side

We would have preferred a system that placed the brackets around the phrase to be moved, and then indicated the insertion point, along the following lines:

I can well imagine that someone [is always in $\operatorname{doubt}(*)$ ] before he opens the door of his house $(*) \ll \downarrow$ as to $\gg$ whether a chasm may not have opened on the other side...

Like most such difficulties with the diplomatic edition, any confusion or unclarity can easily be dispelled by looking at the facsimiles. Indeed even though the diplomatic edition is extremely thorough, it is usually much easier to follow the handwritten corrections in the facsimile. As the normalized edition does not distinguish between Rhees's words and Wittgenstein's revisions, it is not of much interest.

TS 227a is one of the two surviving typescripts of the final version of the Philosophical Investigations. ${ }^{16}$ We checked 11 pages from TS 227a, and found approximately one small transcription error per page. We also noted the mistaken addition of two extra words in the diplomatic edition ('in' on page 90a, line 1; 'leicht' on page 92, line 6). Cross-checking, we noted that both of these mistakes are repeated in the diplomatic edition of TS $227 \mathrm{~b}$, another copy of 227a. This suggested that the transcriptions of the two typescripts are based on one transcription of the shared text.

(C) 2010 Blackwell Publishing Ltd. 
MS 142 is the earliest draft of the Philosophical Investigations, dating from the end of $1936 .{ }^{17}$ In ten pages of MS 142, a heavily revised manuscript volume, we identified sixteen minor errors, and two changes of wordings: 'das uns' in the middle of page 106 is replaced by 'welches' in the transcription; 'Leser' on page 110 is replaced by 'Andre' in the transcription. Noticing that both these changes of wording correspond to the wording of the typescript of the next version of this text, TS 220, we formed the hypothesis that the transcription of MS 142 may have been produced by revising a transcription of TS 220, rather than producing it from scratch. In the best of all possible worlds, such expedients would never be adopted. However, the sheer scale of the project must have required some compromises if it was to be brought in on time. Editors who make use of it will be grateful to have so much of their work done for them. The editing of MS 142 and TS 227 in the critical-genetic edition of the Philosophical Investigations (Wittgenstein 2001) was exemplary; the intricacies of the source text were unraveled with care in unobtrusive footnotes. Scholars who make use of the Bergen Electronic Edition should always check the editing of any passage they study closely, or plan to quote. It should already be clear that it would be a false economy to buy an edition of the Bergen Electronic Edition without the facsimiles. The diplomatic edition is an invaluable guide to the intricacies of the source texts, but no replacement for them.

We also noticed a couple of more general transcription issues in TS 227a. The placement of insertions written above the main line of text appeared to be inconsistently handled in the diplomatic edition: sometimes the insertion is transcribed directly after the word it is written above, but at other times, the insertion is placed at the end of the phrase or sentence in question. It may be that the decision about where to place the insertion turned on which location seemed more plausible, but it was hard to discern a clear pattern, and the issue is not addressed in the front matter. Another transcription problem concerned passages that had a circle drawn around them, such as the top two-thirds of page 113. The diplomatic edition shows this as underlining. This is not only contrary to the explanation of the use of underlining in the key, but also makes it impossible to represent the underlined words within the circled passage appropriately.

The most problematic material we reviewed was TS 233, the source for Zettel. This is a difficult text to transcribe, as it is not, strictly speaking, a conventional typescript, but rather a collection of heavily revised slips of paper, cut from typescripts, that were glued in their current order by Peter Geach. There can be several layers of revision to transcribe, in different inks and often squeezed into the small space available on the slip. We identified approximately 120 mistakes in the 42 pages of the diplomatic edition of TS 233b that we reviewed, including no less than ten on page 38 . While the vast majority were very small, we did find seven passages that had been left out of the diplomatic edition altogether. Also, a couple of substantial passages, each several sentences long, that are shown as insertions in the diplomatic edition (TS 233b, 4a-4b), are not included in the normalized edition. We also noted that the transcription protocol does not distinguish between typed corrections (usually a misspelled word that is crossed out and the correction typed in), and those that are written in later.

TS 235 is a somewhat mysterious document, described by von Wright in his catalogue as a 'Typescript of a Table of Contents to an unidentified work. Date Unknown. 9 pp.'. We were unable to review the editing of this typescript, as the facsimile provided shows a clean typescript, with only a few typed corrections, presumably a carbon copy of the typescript with manuscript corrections noted in the diplomatic edition. This lacuna is not noted in the front matter.

MS 105 is the first of a series of 18 numbered manuscript volumes that Wittgenstein began in February 1929 and continued for over 10 years. It has been published in a

(C) 2010 Blackwell Publishing Ltd. 
scholarly edition as part of the first volume of the Vienna edition, (Wittgenstein 1994). MS 114 is the tenth volume in that series, begun in 1932. We identified an average of only one minor mistake every two pages, and no missing passages, in the 36 pages we reviewed from MS 114, an extensively revised manuscript. However, the facsimile for page 43 is missing, replaced by a second copy of page 44, and this omission is not on the list of missing pages provided in the front matter. While reviewing this material, we did notice some limitations to the transcription system's ability to handle the crossing out of signs and passages. In the case of a deleted dash, or an arrow, the usual method of adding 'strike-through' does not work. In some instances, these problematic deletions are indicated in the diplomatic edition by a ${ }^{\prime \prime}$, but this convention is not used consistently, and not mentioned in the front matter. In the case of a crossed-out paragraph, the transcription conventions do not distinguish between a single line through a paragraph, and a paragraph that has been crossed out, or has many lines through it. It is unfortunate that all 'deleted' passages are treated the same way.

With one exception, we found the transcription of the first 20 pages of MS 105 was to a similarly high standard. One surprising small mistake was that an image of a computer cursor was somehow incorporated into the representation of a logical formula on page $21 .^{18}$ The only substantial omission we noted was the motto, 'Hier hilft dem Dummen die Dummheit allein'. (Here only stupidity helps the stupid), lightly written in pencil under the title of the volume. MS 105 is one of the few volumes for which only low quality black and white photos are provided, and the words are barely visible. However, this motto, taken from Nestroy's play 'Secret Love-Secret Money', and then placed at the very beginning of an eighteen volume series of manuscript notes, is a serious oversight, and means that anyone searching for references to Nestroy will only find a few other references to that author. ${ }^{19}$ A search of the person index yields three hits. Two of these are to the motto of the Philosophical Investigations, on page 1 of TSS 227a and 227b, where it is written in, replacing a typed motto from Heinrich Hertz. The other is to a discussion of the connections between facial physiognomy and music (MS 154: 26v.) However, there is one more reference to Nestroy in the Bergen Electronic Edition, namely a manuscript note of the motto of the Philosophical Investigations, followed by his name in parentheses (MS 134: 152.) While this can be found using a regular search for the word 'Nestroy', it does not show up in a search of the person index, presumably because it was not tagged as a reference to the playwright.

MS 183 contains personal diary entries from the 1930s (published in Wittgenstein 1997, and translated in Wittgenstein 2003). There were about a dozen small mistakes in over forty pages of MS 183, and only one missing phrase; almost all of these errors were corrected in the two-volume Haymon edition of MS 183 (Wittgenstein 1997). The first is a 'normalized' edition, and the second a 'diplomatic' one. However, the 'diplomatic' edition is somewhat more detailed than the version in the Bergen Electronic Edition. It introduces new symbols for crossed out dashes, crossed out underlining, double underlining, single letters that are overwritten with another letter (such as replacing a small ' $a$ ' by a capital ' $\mathrm{A}$ '), and for letters that are written over other letters where the previous letter is no longer legible.

\section{Conclusion}

The Bergen Electronic Edition is an extraordinary editorial achievement. It provides researchers and editors with unprecedented access to Wittgenstein's unpublished writing

(C) 2010 Blackwell Publishing Ltd. 
as a whole. It is a landmark contribution to editing in the humanities, both as a state of the art scholarly edition of the papers of a major figure in the history of philosophy, and as one of the first generation of digital editions of the collected work of a canonical author. It will also be of considerable interest to anyone attending to the problems involved in producing a digital edition of a large and complex Nachlass. The Bergen edition is not a replacement for the published texts; its principal use will be as a resource enabling editors and researchers to work on the sources of those texts. However, by facilitating new editions and new interpretations of Wittgenstein's work, its impact on our understanding of his philosophy will extend beyond the narrow circle of experts who currently make use of it. ${ }^{20}$

\section{David Stern}

Department of Philosophy

The University of Iowa

USA

david-stern@uiowa.edu

\section{NOTES}

${ }^{1}$ For previous discussion, see Hintikka 1991; Kenny 1976, 2005; Stern 1996a, 1996b. The Bergen edition can also be used to review the editing of the published works. While this information is not provided within the digital edition, Biggs and Pichler 1993 provide detailed charts of the Nachlass sources of the published works.

${ }^{2}$ See von Wright 1969. Revised and updated in Wittgenstein 1993a: 480-510 and in Wittgenstein 2003, with an addendum.

${ }^{3}$ The terminology is due to Claus Huitfeldt. See Huitfeldt 1993, 1994a and 1994b.

4 These figures are taken from Huitfeldt 2001.

${ }^{5}$ For further discussion, see Pichler 2002, II; Hrachovec 2000.

${ }^{6}$ For further information, see http://wab.aksis.uib.no/wab_discovery.page and http:// www.discovery-project.eu/. For examples of the various display formats, including interactive

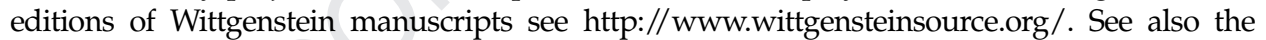
brief HyperWittgenstein project description at http://wab.aksis.uib.no/wab_hw.page/. For further discussion, see Hrachovec 2000, 2005; McEwen 2005; Pichler 2002, 2006.

${ }^{7}$ Hrachovec 2000 reviews some of the difficulties and limitations of using the software on a campus network.

${ }^{8}$ A few pages could not be photographed; these exceptions are listed in the introduction. A few manuscripts could only be reproduced in black and white photographs, with a quality comparable to a microfilm; the color photographs are of considerably better quality, although they do not show some fine details, such as very light pencil marks. For more detailed discussion, see Schulte 2002: 241.

${ }^{9}$ For further information, see Biggs and Pichler 1993, and Biggs 1998, 2001.

${ }^{10}$ For lists of references connecting different stages of revision, see: Maury 1981, 1994; Nedo 1994-, index volumes; Wittgenstein 2001, appendix.

${ }^{11}$ For further information, see above, n6.

12 Some rare exceptions to this rule are the brief but helpful remarks in Schulte 1993: 6-7, Pichler 1994: 2.2, and the preface to The Big Typescript (Wittgenstein 2005: x). See also Paul 2007. Nedo observes that 'Wittgenstein's marginal marks, which in general relate to the relevant remark in toto, present both a form of commentary and indications for further

(C) 2010 Blackwell Publishing Ltd. 
use in revision,' (Wittgenstein 1993b: 100) but to the best of my knowledge does not provide further guidance in construing those remarks.

${ }^{13}$ I would like to express my appreciation for his thorough and painstaking work on this project. I am responsible for any errors in the following discussion. Some of his corrections are noted in the WAB's online error list at errors.htm That list is no longer being updated; future su forthcoming Discovery edition.

${ }^{14}$ Schulte 2002: 240. Other reviews of the Bergen Electronic Edition include Roser 2001, Binder and Haller 2002, McGuinness 2002b, Soulez 2003.

15 See Wittgenstein 2001: 205-446.

16 See Wittgenstein 2001: 739-989.

17 Wittgenstein 2001: 51-204.

18 Because Wittgenstein first wrote on the odd-numbered pages, only filling in the even pages afterwards, page 21 is part of the first 20 pages of this volume. Wisely, the diplomatic transcription follows this order, rather than showing the pages in their physical sequence.

19 The Nestroy passage is included in the Vienna edition (Wittgenstein 1994: volume 1, vii and 1), but is overlooked in Biesenbach's (2008) collection of references and citations in Wittgenstein's work.

20 Mauro Engelmann, Jim Klagge, Alois Pichler, Brian Rogers, Joachim Schulte and George Wrisley provided extremely helpful comments on an earlier version of this paper,

\section{REFERENCES}

Baker, G. and Hacker, P. (1980), An Analytical Commentary on Wittgenstein's Philosophical Investigations. Chicago: University of Chicago Press. [Revised second edition, Oxford: Blackwell, 2005.].

— and - (1984), Scepticism, Rules and Language. Oxford: Blackwell.

Biesenbach, H. (2008), Anspielungen und Zitate im Werk Ludwig Wittgensteins. Internationale Ludwig Wittgenstein Gesellschaft site: http://www.ilwg.eu/

Biggs, M. (1998), 'Ludwig Wittgenstein: A Visual Concordance to the Published Works', Minerva 2, University of Limerick, Ireland. http://www.ul.ie/ philos/vol2/

— (2001), 'Why Study Wittgenstein's Diagrams?', in R. Haller and K. Puhl (eds.) Wittgenstein and the Future of Philosophy: A Reassessment After 50 Years, Vol.1, 95-100. Kirchberg a/W, Austria: Die Österreichische Ludwig Wittgenstein Gesellschaft.

Biggs, M. and Pichler, A. (1993), Wittgenstein: Two Source Catalogues and a Bibliography. Working Papers from the Wittgenstein Archives at the University of Bergen, No. 7. http://wab.aksis.uib.no/wp-no7.pdf

Binder, T. and Haller, R. (2002), 'Wittgensteins Nachlass. The Bergen Electronic Edition', Nachrichten, 10: 98-106.

Hacker, P. (1990), Wittgenstein: Meaning and Mind. An Analytical Commentary on the Philosophical Investigations, vol. 3.. Oxford: Blackwell.

— (1996), Wittgenstein: Mind and Will. An Analytical Commentary on the Philosophical Investigations, vol. 4.. Oxford: Blackwell.

Hallett, G. (1977), A Companion to Wittgenstein's 'Philosophical Investigations'. Ithaca: Cornell University Press.

Hintikka, J. (1991), 'An Impatient Man and His Papers', Synthese, 87: 183-201. [Reprinted as chapter 1 of J. Hintikka (1996) Ludwig Wittgenstein: Half-Truths and One-and-a-HalfTruths. Dordrecht: Kluwer.]

(C) 2010 Blackwell Publishing Ltd. 
Hrachovec, H. (2000), 'Wittgenstein On Line/On the Line' http://wab.aksis.uib.no/ wab_contrib-hh.page (2005), 'Evaluating the Bergen Electronic Edition', in A. Pichler and S. Säätelä (eds), Wittgenstein: The Philosopher and his Works. Working Papers from the Wittgenstein Archives at the University of Bergen no. 17, 364-76. Bergen: Wittgenstein Archives at the University of Bergen.

Huitfeldt, C. (1993), MECS - A Multi-Element Code System. Bergen: Wittgenstein Archives at the University of Bergen.

- (1994a), 'Multi-dimensional Texts in a One-dimensional Medium', Computers and the Humanities, 284/5: 235-41.

(1994b), ‘Toward a Machine-Readable Version of Wittgenstein's Nachlaß: Some Editorial Problems', in Hans Gerhard Senger (ed.) Philosophische Editionen. Erwartungen an sie - Wirkungen durch sie, 37-43. T ü bingen: Max Niemeyer Verlag.

- (2001), 'The Bergen Electronic Edition of Wittgenstein's Nachlass'. Lecture in Bergen, December 13, 2001. Link to audio recording: http://wab.aksis.uib.no/w-konferanse/

Kenny, A. (1976), 'From the Big Typescript to the Philosophical Grammar', Acta Philosophical Fennica, 28: 41-53. [Reprinted in A. Kenny (1984), The Legacy of Wittgenstein, 24-37. Oxford: Blackwell.].

— (2005), 'A Brief History of Wittgenstein Editing', in A. Pichler and S. Säätelä (eds), Wittgenstein: The Philosopher and his Works. Working Papers from the Wittgenstein Archives at the University of Bergen no. 17, 341-55. Bergen: Wittgenstein Archives at the University of Bergen.

Maury, A. (1981), 'Sources of the Remarks in Wittgenstein's Zettel', Philosophical Investigations, 4: 57-74.

— (1994), 'Sources of the remarks in Wittgenstein's Philosophical Investigations', Synthese, 90: 349-78.

McEwen, C. (2005), 'Wittgenstein in Digital Form: Perspectives for the Future', in A. Pichler and S. Säätelä (eds), Wittgenstein: The Philosopher and his Works. Working Papers from the Wittgenstein Archives at the University of Bergen no. 17, 377-89. Bergen: Wittgenstein Archives at the University of Bergen.

McGuinness, B. (2002a), Approaches to Wittgenstein: Collected Papers. London: Routledge.

- (2002b), 'The Other Side of Silence', Times Literary Supplement, June 14: 3-4.

Paul, D. (2007), Wittgenstein's Progress 1929-1951. Bergen: Publications from the Wittgenstein Archives at the University of Bergen.

Pichler, A. (1994) Untersuchungen zu Wittgensteins Nachlass. [Investigating Wittgenstein's Nachlass.] Working Papers from the Wittgenstein Archives at the University of Bergen 8. http://wab.aksis.uib.no/wp-no8.pdf

- (2002), 'Encoding Wittgenstein: Some Remarks on Wittgenstein's Nachlass, the Bergen Electronic Edition, and Future Electronic Publishing and Networking', E-publication: http://www.inst.at/trans/10Nr/pichler10.htm. In: TRANS. Internet-Zeitschrift für Kulturwissenschaften 10/2001ff.

- (2006), 'What Can/Shall the Next Bergen Electronic Edition(s) Look Like?' Paper presented at the 29th International Wittgenstein Symposium 'Cultures: Conflict-Analysis-Dialogue', org. Georg Gasser, Christian Kanzian and Edmund Runggaldier.

Robinson, P. (1997), 'New Directions in Critical Editing', in K. Sutherland (ed) Electronic Text-Investigations in Method and Theory. Oxford: Oxford University Press.

Rothhaupt, J. (1996), Farbthemen in Wittgenstein's Gesamtnachlass. Weinheim: Beltz Athenäum Verlag, pp. 327-39.

(C) 2010 Blackwell Publishing Ltd. 
- (2008), Kreation und Komposition: Philologisch-philosophische Studien zu Wittgensteins Nachlass (1929-1933). Habilitationsarbeit, Ludwig-Maximilians-Universität München.

Roser, A. (2001), 'Wittgensteins Nachlass auf CD-ROM', Information Philosophie.

Schulte, J. (1987), Erlebnis und Ausdruck: Wittgenstein's Philosophie der Psychologie. M ü nchen: Philosophia.

- (1993), Experience and Expression: Wittgenstein's Philosophy of Psychology. New York: Oxford University Press. [Translation of J. Schulte (1987), Erlebnis und Ausdruck: Wittgenstein's Philosophie der Psychologie. München: Philosophia.].

_ (2002), 'Wittgenstein's Nachlass: The Bergen Electronic Edition', Grazer Philosophische Studien, 65: 237-46.

Soulez, A. (2003), 'Le CD-Rom Wittgenstein: 1'histoire du Nachlass', Revue de Métaphysique et de Morale, 37: 107-11.

Stern, D. G. (1996a), 'The Availability of Wittgenstein's Philosophy', in Hans Sluga and David G. Stern (eds.), The Cambridge Companion to Wittgenstein. Cambridge: Cambridge University Press, 442-76.

(1996b), 'Towards a Critical Edition of the Philosophical Investigations', in K. S. Johannessen and T. Nordenstam (eds), Wittgenstein and the Philosophy of Culture, 298309. Vienna: Hölder-Pichler-Tempsky.

Q6 - (2008), 'Digital Wittgenstein Scholarship: Past, Present and Future', in A. Pichler and H. Hrachovec (eds) Wittgenstein and the Philosophy of Information: Proceedings of the 30th International Wittgenstein Symposium, volume 1. Frankfurt: Ontos Verlag: 223-38.

Von Wright, G. H. (1969), 'The Wittgenstein Papers', Philosophical Review, 78: $483-503$. Considerably modified in Wittgenstein (1993) 480-510. With an addendum in Wittgenstein 2003 .

(1982), Wittgenstein. Oxford: Blackwell.

Wittgenstein, L. (1922), Tractatus Logico-Philosophicus, translation on facing pages by C. K. Ogden. London: Routledge and Kegan Paul. Second edition, 1933.

(1953), Philosophical Investigations, edited by G. E. M. Anscombe and R. Rhees, translation on facing pages by G. E. M. Anscombe. Oxford: Blackwell. Second edition, 1958. Revised edition, 2001.

(1993a), Philosophical Occasions, 1912-1951, eds. James Klagge and Alfred Nordmann. Indianapolis, IN: Hackett.

(1993b), Wiener Ausgabe [Vienna Edition] Introduction, ed. Michael Nedo. Vienna: Springer.

(1994-), Wiener Ausgabe [Vienna Edition], multiple volumes, ed. Michael Nedo. Vienna: Springer.

- (1997), Denkbewegungen: Tagebücher 1930-1932, 1936-1937 (MS 183). ed. Ilse Somavilla. Innsbruck: Haymon.

- (2001), Philosophische Untersuchungen. Kritisch-genetische Edition [Philosophical Investigations. Critical-genetic edition] ed. Joachim Schulte. Frankfurt: Suhrkamp.

(2003), Ludwig Wittgenstein: Public and Private Occasions, ed. James Klagge and Alfred Nordmann. Lanham, MD: Rowman \& Littlefield Publishers.

- (2004), Briefwechsel Innsbrucker elektronische Ausgabe [Correspondence, Innsbruck Electronic Edition], eds Monika Seekircher, Brian McGuinness and Anton Unterkircher. Charlottesville, VA.: Intelex.

— (2005), The Big Typescript, eds C.G. Luckhardt and M.A.E. Aue. Oxford: Blackwell.

(C) 2010 Blackwell Publishing Ltd. 


\section{Author Query Form}

\begin{tabular}{ll}
\hline Journal & EJOP \\
Article & 425
\end{tabular}

Dear Author,

During the copy-editing of your paper, the following queries arose. Please respond to these by marking up your proofs with the necessary changes/additions. Please write your answers clearly on the query sheet if there is insufficient space on the page proofs. If returning the proof by fax do not write too close to the paper's edge. Please remember that illegible mark-ups may delay publication.

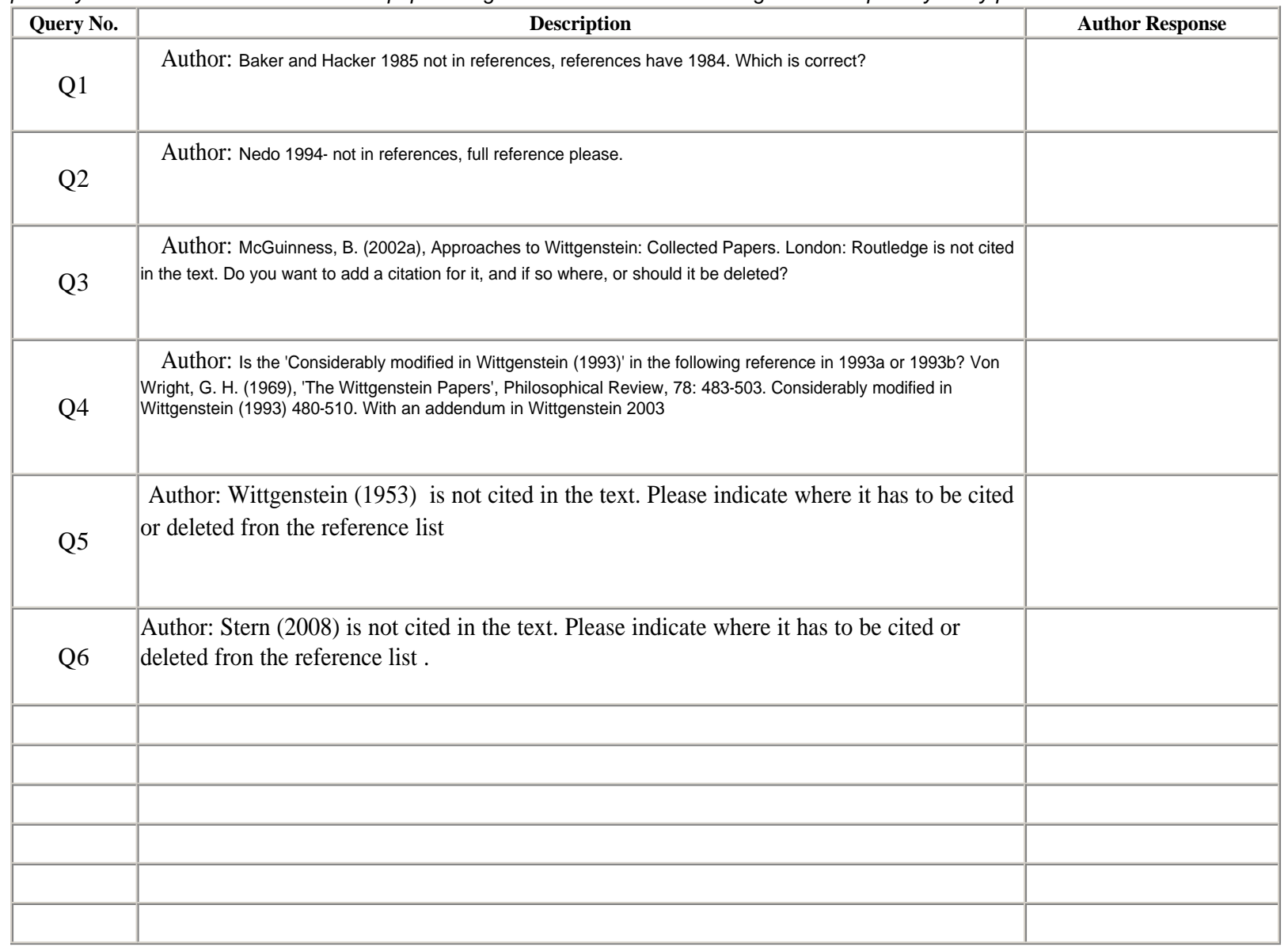

